\title{
Clinical indicators: do we know what we're doing?
}

After recent publicity surrounding the verdict of the General Medical Council on the case of 2 surgeons, 1 manager from Bristol with high perioperative mortalities, ${ }^{1}$ there is mounting pressure on the National Health Service (NHS) in England and Wales to make explicit information publicly available on standards of care at a procedure, hospital, and even consultant level. In theory, this could be used by patients (and others - such as healthcare commissioners) to make an informed choice about where treatment should occur and who should do it. However, whether or not choices of this kind can be better made by use of such data is unresolved.

Demand for performance indicators is not new; nor is the controversy surrounding their use. ${ }^{2}$ However, the emphasis on public accountability and the right of consumers to have access to information has continued to grow across health care internationally. The NHS in England and Wales has now announced that it will publish hospital based clinical indicators in October 1998, including mortalities for surgical interventions, ${ }^{3}$ as part of the recently announced performance management framework, ${ }^{4}$ and in response to recent public and political pressure arising from the Bristol case. This reflects similar moves in other countries including Scotland, where clinical indicator measures have been published for several years, ${ }^{5-7}$ and Italy, where an ambitious programme is planned. ${ }^{89}$ Although these developments proceed apace, we should perhaps take greater note of the less than encouraging experience of publicising such data in the United States. ${ }^{10}{ }^{11}$

In this issue, Davies and Lampel discuss the recent and continuing explosion in publicly available performance measures and the increasing emphasis on measuring outcome. ${ }^{12}$ They eloquently review the potential problems with this approach. In particular, they point out that the method is more one of retrospective detection of error, rather than an attempt to prospectively build in quality. Furthermore, it is clear that there are serious problems with the quality of routinely available data and a disturbing potential to encourage inappropriate changes in behaviour. ${ }^{13}$ Davies and Lampel argue that instead of more and more indicators being developed, collected, and refined, we should take a wider, more radical, view of how quality improvement can best be facilitated in the complex setting of health care.

We now work in a healthcare system that is increasingly and rightly charged with making clinical decisions based on reliable evidence. ${ }^{14}$ Others have argued for a similar rigour in healthcare policy making. ${ }^{15}$ Much of the current evidence on the effectiveness of performance indicators is based on observational or experiential data, although much of the policy agenda in this area seems to be based at its worst on dogma. Although observational or experiential data should not be lightly dismissed, the limited evidence base in this area underlines the need for more research, particularly using robust methods-such as randomised controlled trials - to further evaluate the use of indicators. Such work would need to be appropriately supported by systematic qualitative methods to understand better the factors that influence the effectiveness (or otherwise) of use of indicators. ${ }^{16}$ Only by funding and carrying out such research will we be able not only to determine how best to use performance indicators to create appropriate change, but also describe the circumstances and settings in which they are most likely to be effective.
There are many challenges in undertaking research in an area such the use of indicators. For example, a major debate highlighted by the work of Davies and Lampel and others lies in whether comparative indicators should be made publicly available - such as in the patient's charter in the United Kingdom, ${ }^{17}$ the Clinical Outcome Indicator package in Scotland, ${ }^{5-7}$ or the approach of certain states in the United States - such as Pennsylvania ${ }^{18}$ - or whether they would be better used internally-such as the Maryland Hospital Association Quality Indicator Project and the United Kingdom Quality Indicator Project ${ }^{19}$-albeit to support publicly accountable quality systems. In the United Kingdom, there is a danger that this important debate will become submerged under the considerable media and political attention surrounding the Bristol case.

Despite the considerable challenges of carrying out robust research on complex interventions such as this, such work is desperately needed. Indeed, with the Department of Health in England and Wales about to publish comparative clinical indicators, there is an unparalleled opportunity. It would be feasible to randomise NHS hospitals to either public or internal availability of data in a nationwide trial, before deciding which approach we would best pursue in an effort to improve quality of care for our patients. However, despite the evidence-based movement, we fear that political expediency will override policy rigour in the current climate.

RICHARD THOMSON

Senior Lecturer in Public Health Medicine, Director, UK Quality Indicator Project

JOANNE LALLY

Research Associate, Coordinator, UK Quality Indicator Project, Department of Epidemiology and Public Health, The Medical School, Nerwcastle Upon Tyne, UK

1 Treasure T. Lessons from the Bristol case. BMF 1998;316:1685-6.

2 Pollitt C. Measuring performance: a new system for the national health service. Policy and Politics 1985;13:1-15.

3 Warden J. Hospital death rates to be published for England. BMF 1998;316: 1767.

4 Department of Health. The new NHS modern and dependable: a national framework for assessing performance. London: Department of Health, 1998.

5 Clinical Outcomes Working Group. Clinical outcome indicators. Edinburgh: The Scottish Office Clinical Resource and Audit Group, 1994.

6 Clinical Outcomes Working Group. Clinical outcome indicators. Edinburgh: The Scottish Office Clinical Resource and Audit Group, 1995.

7 Clinical Outcomes Working Group. Clinical outcome indicators. Edinburgh: The Scottish Office Clinical Resource and Audit Group, 1996

8 Mariotto A, Chitarin M. External evaluation of health care in Italy. Quality in Health Care 1998;7:168.

9 Thomson R, Lally J. Comment. Quality in Health Care 1998;7:168-9.

10 McKee M, Hunter D. Mortality league tables: do they inform or mislead? Quality in Health Care 1995;4:5-12.

11 McKee M. Indicators of clinical performance. BMF 1997;315:142.

12 Davies HTO, Lampel J. Trust in performance indicators? Quality in Health Care 1998;7:159-62.

13 Davies HTO, Crombie IK. Interpreting health outcomes. Fournal of Evaluation in Clinical Practice 1997;3:187-99.

14 Rosenberg W, Donald A. Evidence based medicine: an approach to clinical problem solving. BMF 1995;310:1122-6.

15 Ham C, Hunter DJ, Robinson R. Evidence based policymaking. BMF 1995; 310:71-2.

16 Pope C, Mays N. Reaching the parts other methods cannot reach: an introduction to qualitative methods in health and health services research. $B M \mathcal{F}$ 1995;311:42-5.

17 Department of Health. The patient's charter: raising the standard. London: HMSO, 1991

18 Boyce N. North American insights into quality and outcome: indicators in acute healthcare services. In: Boyce N, McNeil J, Graves D, et al, eds. Quality and outcome indicators for acute healthcare services. Canberra: Australian Government, 1997.

19 Thomson RG, McElroy H, Kazandjian VA. Maryland Hospital Quality Indicator Project in the United Kingdom: an approach for promoting continuous quality improvement. Quality in Health Care 1997;6:49-55. 